\title{
Mais um ministério de farda: coronavírus e militarismo, a dupla carga epidêmica sobre a Saúde
}

| ${ }^{1}$ Leandro A. Pires Gonçalves |

1 Instituto de Saúde Coletiva, Universidade Federal Fluminense. Rio de Janeiro-RJ, Brasil (leandroapg@id.uff.br). ORCID: 0000-0002-6795-8374

Recebido em: 25/06/2020

Aprovado em: 15/07/2020

Revisado em: 18/09/2020

DOI: http://dx.doi.org/10.1590/S0103-73312020300401

Alguns eventos históricos causam sensação de perplexidade em quem revisita seus registros ou lê seus narradores e analistas. $\mathrm{O}$ fenômeno nazista é, talvez, aquele que foi mais bem registrado, analisado e o que produziu maior enfrentamento ético e político no seu pós. Outro exemplo menos consensual foi o fenômeno colonizador das "Américas", "Áfricas" e "orientes", que não teve o mesmo tratamento e está aí até hoje produzindo perplexidades para alguns e comemoraçóes para outros. Nos dois fenômenos mencionados, milhóes de pessoas foram mortas de maneira organizada por grupos que tinham o racismo e a acumulaçáo capitalista como princípios éticos e políticos. Perguntamo-nos: como as pessoas que não estavam envolvidas diretamente no operar nazista e no colonial permitiram e foram capazes de viver em meio a tamanha atrocidade?

O presente nos permite enfrentar essa pergunta, ainda que, antes que respostas concretas, nos provoque outras questôes. No Brasil, há pelo menos seis meses, um presidente e seus asseclas boicotam sistematicamente a resposta que o próprio Estado que ele lidera faz da epidemia do novo coronavírus (SARS-CoV-2). Desde junho de 2020, vemos o Brasil com número de novos casos e mortes em patamares altos e constantes, disputando com os Estados Unidos (EUA) a liderança nos balanços 
diários de novos casos e mortes entre todos os países. E Jair Bolsonaro segue boicotando as respostas à epidemia e inventando soluçóes salvadoras para que a economia brasileira volte a um patamar de plenitude - que antes da epidemia já estava longe de pleno (BARBOSA, 2020). Morrem no Brasil cerca de mil pessoas por dia e Bolsonaro ordena que ponham cloroquina na cesta básica dos brasileiros (SILVA; GONÇALVES, 2020). O Brasil não pode parar.

Como o presidente de um país é capaz de causar mortes e profanar diariamente milhares de mortos e a dor das pessoas que lhes queriam bem? Ele teria uma maioria que o apoia e o sustenta? Sobre a última pergunta, as pesquisas de opinião recentes apontam que sua aprovaçáa é crescente, após um período de queda entre março e julho. Cerca de $49 \%$ da população aprova Bolsonaro e 38\% das pessoas acham seu governo "ótimo" ou "bom", conforme pesquisa da agência PoderData (FREIRE, 2020). Claro, pesquisas de opinião são frágeis, não devemos assumi-las acriticamente (ROMAN, 2020). Mas assustam. De todo o modo, 49\% de aprovação não significam que uma maioria consistente o apoie.

Em um país que acabou de perder cerca de 140 mil pessoas, Bolsonaro segue bravateando. Diante das mortes, depois do consagrado "e daí?", agora diz que o Brasil está "praticamente vencendo a pandemia” (ANDRADE, 2020). E segue sua jornada heroica e participante de atos semanais em seu nome. Como tem dito Vladmir Safatle, parece que a terça parte dos brasileiros que o elegeram e o apoiavam rapidamente caminham para se tornar seus adoradores (BARROCAL, 2020), seguindo-o obstinadamente. As evidências disso estão aí intensas, vibrantes em neon. A partir deste ponto, vou desdobrar uma dessas evidências, a que considero mais preocupante, pois atinge as instituiçôes da Saúde no momento sanitário mais crítico de nossas vidas. Bolsonaro conduziu, blefando com a atual epidemia e fritando técnicos, a ocupação do Ministério da Saúde por militares e sua transformação em caserna.

\section{$\mathrm{O}$ vestir da farda}

Luiz Henrique Mandetta foi nosso ministro da Saúde entre janeiro de 2019 e abril de 2020. Nesse período, foi considerado um ministro técnico, por ser médico, e da cota "política" do governo, pois havia sido indicado pelo partido Democratas (SHALDERS, 2018). Portanto, não se tratava de um amigo direto do presidente; compunha o governo sem fazer grandes estardalhaços públicos, com bom trânsito entre os poderes e estruturas administrativas do Sistema Único de Saúde (SUS). 
Bom trânsito e pouco estardalhaço que aproveitou para liderar, no pré-epidemia, um consistente conjunto de esforços para desfinanciar e reestruturar a Atenção Básica à Saúde no Brasil (NEVES; MACHADO, 2019). O SARS-CoV-2 aportou no Brasil com gestores de todos os entes federados incertos sobre o financiamento da Atenção Básica e profissionais que compunham o modelo Saúde da Família sendo demitidos ou deslocados de suas atribuições cotidianas. Seu secretário de Atenção Primária à Saúde, Erno Harzheim, compartilhava com colegas médicos no Congresso Brasileiro de Medicina de Família e Comunidade, em julho de 2019, a direção tomada pelo Ministério da Saúde: "Estamos aqui para implementar um sistema de saúde liberal. O SUS não tem que ser para todos, mas apenas para aqueles que não conseguem proteger a si próprios. Quem quiser discutir universalidade, volte para a década de 20" (SAÚDE POPULAR, 2019).

Este era o ministério de Mandetta quando o novo coronavírus chegou ao Brasil. Subitamente, diante do risco sanitário e do temor de colapso provocado nos setores tradicionalmente representados por Mandetta, os hospitais filantrópicos e a medicina de grupo, como as Unimeds, este vestiu a jaquetinha do SUS. Mandetta usou suas credenciais de operador do sistema vigente e habilidades políticas para liderar uma resposta à epidemia pelo SARS-CoV-2 que foi, no mínimo, responsável (BENITES; GORTÁZAR, 2020). Ainda que seu trabalho fosse garantir e intensificar o SUS como uma espécie de resseguro do setor privado, como nas últimas décadas (BAHIA, 2019; KISS; GONÇALVES, 2020), Mandetta passou a se apoiar nas evidências científicas e experiências logísticas dos principais sistemas de saúde do mundo para planejar açôes. O ministro fazia comunicados diretos e diários sobre o avanço da epidemia no território nacional e dos trabalhos de resposta do SUS. Mesmo que as notícias não fossem fáceis e as açôes acanhadas, Mandetta conduzia com segurança o processo e tornou-se popular. Sua condução chegou a ser aprovada por $76 \%$ dos brasileiros.

Se a consistência técnica e política era reconhecida pela população, o presidente Bolsonaro desqualificava diariamente o ministro Mandetta. Dizia à imprensa que ninguém é insubstituível, que o ministro se comportava como uma estrela, que queria "aparecer"; que a doença era como uma "gripezinha", que a cloroquina era sua solução e que a população produtiva brasileira não sofreria maiores consequências, pois a Covid-19 afetava "velhos" e que cada família se responsabilizasse pelos seus; que a principal medida de enfrentamento à epidemia tomada no Brasil, o distanciamento 
amplo, mataria mais que o próprio vírus por paralisar a economia; promoveu a campanha "O Brasil não pode parar" e convocou milhares de apoiadores seus para fazer carreatas por todo o Brasil (BERTONI, 2020a; 2020b). Os termos usados pelo presidente foram esses, não há exagero aqui. $\mathrm{O}$ processo de fritura do ministro operado por Bolsonaro durou cerca de dois meses, com capítulos diários veiculados nas mídias e redes sociais, como um folhetim. Por fim, ainda bastante popular, Mandetta caiu.

Contrariando a expectativa de muitos, que esperavam uma queda na popularidade de Bolsonaro e uma mudança no seu discurso, nada passou a ser diferente. O presidente convidou outro ministro técnico, por ser médico, Nelson Teich. Este, contudo, tem pouco traquejo político e é um "corpo estranho" às estruturas institucionais do SUS. Teich seguiu as principais diretrizes apontadas anteriormente por Mandetta, só que sem o vigor do ministro anterior. E Bolsonaro seguiu fritando-o, deslegitimando a condução do ministro e sequer comunicando-lhe previamente sobre decisóes da área econômica que afetavam sua pasta. Teich entrou em abril e pediu exoneração em maio, tão cabisbaixo quanto entrou (GAGLIONI, 2020).

Entre Mandetta e Teich havia uma diferença importante: Mandetta tinha uma equipe técnica a qual ele prezava e preservava nas suas secretarias. Não foram poucas as falas do ex-ministro sobre a importância dessa equipe e o pacto que havia entre o ministro e seus secretários. Era o trabalho dessa equipe que provia consistência técnica à atuação de Mandetta. Quando o ministro sugeriu pela primeira vez a própria demissão, falou que sairia com sua equipe; quando, por isso, Wanderson Oliveira pediu demissão da Secretaria de Vigilância em Saúde (SVS), fez o secretário rever sua decisão (JUCÁ, 2020). Hoje, à luz dos acontecimentos de tentativa de intervenção do presidente na Polícia Federal, da saída de Sergio Moro do Ministério da Justiça e Segurança Pública e do que aconteceu no próprio Ministério da Saúde após a saída de Mandetta, podemos deduzir que a fidelidade pública de Mandetta a seus secretários não era só uma demonstração de respeito e justa homenagem. Provavelmente era um recado enviado em cadeia nacional diretamente ao presidente da República: na Saúde, não haveria interferência bolsonarista.

Teich não era do métier, não tinha equipe. Assumiu no dia 17 de abril e ficou com parte da equipe técnica anterior, realocou alguns nomes e nomeou outros. Na Secretaria-Executiva da Saúde, tida como a mais importante por ser o centro operador de toda a pasta, manteve José Gabbardo dos Reis, secretário indicado por Mandetta, durante cinco dias. Em 22 de abril, dia do "descobrimento" do Brasil 
e da fatídica reunião ministerial, o general Eduardo Pazuello foi nomeado no seu lugar. Com experiência em logística e açôes de emergência no exército, Pazuello vinha chancelado por ter coordenado operacionalmente a Força-Tarefa Logística Humanitária Operação Acolhida, em Roraima, que tinha por objetivo realocar no Brasil cidadãos venezuelanos em fuga do seu país natal; outra chancela importante foi a do próprio presidente Jair Bolsonaro, com quem o general tinha conversado no dia anterior, por mediação dos ministros militares do governo (CARVALHO; FERNANDES; CANCIAN, 2020).

Entre 22 de abril e 13 de maio de 2020, Teich nomeou sete militares para cargos estratégicos no Ministério da Saúde. Contraposto nas coletivas de imprensa quanto à militarização do ministério, o ministro respondia, contrariado, que os militares cumpriam uma função temporária durante a resposta à epidemia e logo voltariam ao Exército (GAGLIONI, 2020). Contudo, entre os secretários estaduais e municipais de Saúde, já estava claro que Teich não dava as cartas no ministério, parecia "perdido" e não tinha respostas consistentes nas reuniōes interfederativas (ESTADÃO, 2020). Em 15 de maio, Teich caiu e assumiu o "ministro interino" Eduardo Pazuello. Entre 15 e 20 de maio, Pazuello nomeou mais 13 militares para cargos estratégicos, e em 22 de maio Bolsonaro declarou vida longa ao novo ministro, pois a gestão civil do ministério "não deu certo" (GULLINO, 2020). Em 9 de junho, quase um mês depois de o interino assumir a pasta, o presidente dava sinais de estar muito satisfeito com a condução militar do ministério (ARAÚJO, 2020). Um ministério que, àquela época, esvaziava os balanços diários sobre o avanço da epidemia no Brasil e contradizia seus próprios números (CARVALHO, 2020), gerando incerteza sobre como estávamos e produzindo materiais diários para a máquina de informaçôes falsas que inflama negacionistas e torna o enfrentamento à epidemia uma tarefa quixotesca. Em 16 de setembro, após quatro meses de interinidade, Pazuello tornou-se efetivamente nosso ministro da Saúde, tendo como principal mérito a flexibilizaçáo e o incentivo ao uso de cloroquina em casos leves e desde os primeiros sintomas da Covid-19 (AGÊNCIA BRASIL, 2020).

\section{O que miram os militares?}

O Ministério da Saúde está hoje sob intervenção militar. É mais uma entre tantas outras pastas do Executivo Federal sob ocupação militar. Entretanto, gostaria de chamar a atenção para algumas nuances preocupantes dessa chegada militar ao MS. 
Primeiro: a Saúde é historicamente ocupada por gestores civis e técnicos, quase todos médicos, alguns com formação em Saúde Pública; desde a Constituição de 1988, o MS esteve implicado na proposição, construção e consolidação do SUS, com muitos desvios de rota e direçôes contraditórias, mas nunca houve uma oposição explícita ao direito social e universal à saúde, uma das conquistas mais ousadas da nossa Carta Magna - conquista de um movimento, o Movimento pela Reforma Sanitária Brasileira (MRSB), que se constituiu, resistiu e se opôs à ditadura militar, sendo parte importante no processo de redemocratização do país (PAIM, 2008). Os militares ocuparem o MS hoje é de um peso político e simbólico imenso.

A segunda nuance, já indicada anteriormente, é que até mesmo neste governo a Saúde era, até abril de 2020, a pasta mais preservada. A condução era civil e, ainda que operasse retrocessos para o SUS, tudo era feito por dentro da institucionalidade vigente há pelo menos três décadas. A terceira nuance, a que mais preocupa, é que Bolsonaro e seus colegas militares conseguiram operar essa ocupação sob muita tensão. O presidente atravessa a maior tragédia sanitária de nossas vidas, provocando morte, colhendo e desdenhando dessas mortes, derrubando ministros populares, enfrentando governadores e prefeitos populares e, ainda assim, avançando na ocupação bolsonarista do Executivo Federal. No mês de maio, quando se esperava a derrocada de Bolsonaro pela sua responsabilização quanto a nossa tragédia sanitária, ele e sua tropa avançaram sobre o Ministério da Justiça e Segurança Pública, sobre a Polícia Federal e sobre o Ministério da Saúde. Parece alguma criatura mítica que se alimenta de mortes e destruição, que se fortalece com a tragédia. Que forças podemos opor ao seu avanço?

Apesar de parecer sobrenatural, Bolsonaro não o é. Para entender a construção dessa criatura, vale fortemente recorrer à entrevista do antropólogo Piero Leirner para a agência Pública (DOMENICI, 2019). Leirner, que vem estudando as instituiçôes militares brasileiras e acompanhando seu movimento político nos últimos anos, situa Bolsonaro como um performer a serviço de um movimento corporativo militar que atua com táticas e estratégias de "guerra híbrida". Usando a máquina de comunicação operada nas variadas redes sociais da atualidade, alimentando medos, frustraçóes e ansiedades nas pessoas, Bolsonaro produz peças que se articulam a essa máquina de maneira coerente, junto às famosas fake news. Ao seu lado, mas aparentemente distantes e dando o tom racional do governo, os militares descolam-se da sua imagem, o que fica mais claro na atuação "à paisana” de Hamilton Mourão. Apesar 
da aparente distância, Bolsonaro forma com eles um bloco que atua junto, com método. Leirner dá detalhes impressionantes da formação e atuação desse bloco. Para quem viu a perturbadora reuniáo ministerial do dia 22 de abril, pôde constatar que o bloco senta junto à mesa.

Essa atuação aparentemente dissociada do bloco militar no poder vem confundindo a todos. A imprensa, sempre em busca de notícias quentes e que produzem likes e compartilhamentos, entra nessa engrenagem de maneira indireta, mas importante, retomando sistematicamente a narrativa golpista, como se Mourão estivesse palitando os dentes enquanto cozinha Bolsonaro em "banho-maria" para comê-lo de prato principal. Até mesmo os seguidores do "mito" creem nisso; já os partidos de esquerda e seus representantes, através de seus frágeis canais de comunicação, caem na mesma fantasia, talvez por ainda estarem presos ao desfecho dado em 2016 ao governo Dilma Rousseff. Ora, tal fantasia pôde ser rapidamente dissipada quando Hamilton Mourão, no dia 14 de maio, soou sua trombeta no jornal $O$ Estado de São Paulo, através do artigo "Limites e responsabilidades", avisando a todos os que estão em oposição ao governo que devem abaixar suas armas (MOURÃO, 2020). É guerra sim, e o bloco militar governante está fechado, coeso.

No entanto, nem tudo está perdido e Leirner dá boas pistas se quisermos enfrentar esse bloco militar. Até aqui, ninguém compreendeu muito bem o papel estratégico que teve para esse bloco o general Sérgio Etchegoyen, que foi chefe do Estado Maior do Exército ainda no governo Dilma e assumiu o Gabinete de Segurança Institucional da Presidência da República assim que Michel Temer assumiu a presidência interinamente, em 12 de maio de 2016. Etchegoyen ganhou poderes nesse período, operou mudanças institucionais importantes e preparou a cama para o governo Bolsonaro. Além disso, não temos atentado para as fissuras internas às próprias Forças Armadas, pois esse bloco que está no poder representa frações e certas perspectivas da corporação, com as quais nem todos estáo de acordo, sendo as instituiçôes militares ricas em rivalidades internas e questôes problemáticas relativas à hierarquia.

Para concluir, retomo a questão posta nos primeiros parágrafos deste ensaio: como permitimos e somos capazes de viver diante de tamanha atrocidade? Bolsonaro é diretamente responsável pela tragédia sanitária que vivemos, isso está claro. $\mathrm{O}$ absurdo está em curso, não há como diminuir o que vivemos. Este governo é genocida e aposta na morte de pessoas e populaçôes vulnerabilizadas. Para o presidente e sua tropa, esta não é uma consequência ruim, é a solução sanitária encontrada para 
os problemas sociais e econômicos do país. A necrofilia do vírus se articula aos necrófilos que ascenderam ao poder, estabeleceram uma necro-parceria.

Como metade da população é capaz de dar sustentação a esse absurdo? Essa é uma conta que não fecha pelo padrão algébrico. Só numa escala algorítmica podemos começar a entender o fenômeno. O velho padrão da guerra por outros meios, suas táticas e estratégias, se atualiza nas ferramentas tecnológicas contemporâneas, incorpora-se a nós no formato Android.

Hoje nossa saúde está atravessada por inúmeros condicionantes que extraem nossa vitalidade corporal e coletiva. Podemos ver com nitidez que o processo saúdedoença precisa ser entendido de maneira integral. A virulência do SARS-CoV-2 é proporcional aos traumas que não fomos capazes de elaborar coletivamente. Se os militares um dia silenciaram e mataram com técnicas diretas de tortura nos nossos corpos, hoje pegam carona no avanço de um vírus para nos silenciar e matar. Eles usarão tudo o que é destrutivo a seu favor. Cabe a nós preservar e potencializar a vida. Como começar?

\section{Referências}

AGÊNCIA BRASIL. Eduardo Pazuello toma posse como ministro da Saúde. Portal Agência Brasil, 2020. Disponível em: https://agenciabrasil.ebc.com.br/saude/noticia/2020-09/ao-vivoeduardo-pazuello-toma-posse-como-ministro-da-saude . Acesso em: 18 set. 2020.

ANDRADE, H. Com 129 mil mortes e PIB em queda, Bolsonaro diz que Brasil vence pandemia. Portal UOL, 2020. Disponível em: https://noticias.uol.com.br/politica/ultimasnoticias/2020/09/11/bolsonaro-pandemia-brasil.htm?cmpid=copiaecola. Acesso em 19 set. 2020. ARAÚJO, C. Pazuello, o ministro interino que deixa Bolsonaro satisfeito e sem pressa. Portal UOL, 2020. Disponível em: https://economia.uol.com.br/colunas/carla-araujo/2020/06/09/ coronavirus-pazuello-faz-bolsonaro-sem-pressa-para-escolher-ministro-saude. htm?cmpid=copiaecola . Acesso em: 10 jun. 2020.

BAHIA, L. Planos de saúde privados são predadores do SUS. Portal LE MONDE diplomatique BRASIL, 2019. Disponível em: https://diplomatique.org.br/planos-de-saude-privados-saopredadores-do-sus/ . Acesso em: 24 maio 2020.

BARBOSA, B. Dados de emprego do Caged comprovam falácia do discurso de Guedes em Davos. Portal CARTA MAIOR, 2020. Disponível em: https://www.cartamaior.com.br/?/ Editoria/Politica/Dados-de-emprego-do-Caged-comprovam-falacia-do-discurso-de-Guedesem-Davos/4/46371. Acesso em: 25 maio 2020. 
BARROCAL, A. "Bolsonaro se vê à frente de uma revolução em marcha e não vai parar". Portal CARTA CAPITAL, 2020. Disponível em: https://www.cartacapital.com.br/politica/bolsonarose-ve-a-frente-de-uma-revolucao-em-marcha-e-nao-vai-parar/. Acesso em: 24 maio 2020.

BENITES, A.; GORTÁZAR, N. G. Mandetta, o conservador que vestiu o colete do SUS e entrincheirou Bolsonaro. Portal El País, 2020. Disponível em: https://brasil.elpais.com/ brasil/2020-04-04/mandetta-o-conservador-que-vestiu-o-colete-do-sus-e-entrincheiroubolsonaro.html . Acesso em: 24 maio 2020.

BERTONI, E. Como o avanço da pandemia revela um cenário alarmante no Brasil. Portal NEXO, 2020a. Disponível em: https://www.nexojornal.com.br/expresso/2020/05/23/Como-oavan\%C3\%A7o-da-pandemia-revela-um-cen\%C3\%A1rio-alarmante-no-Brasil . Acesso em: 24 maio 2020 .

. O impacto da campanha 'Brasil não pode parar' de Bolsonaro. Portal NEXO, 2020b. Disponível em: https://www.nexojornal.com.br/expresso/2020/03/27/O-impacto-dacampanha-\%E2\%80\%98Brasil-n\%C3\%A3o-pode-parar\%E2\%80\%99-de-Bolsonaro . Acesso em: 24 maio 2020.

CARVALHO, D.; FERNANDES, T.; CANCIAN, N. Bolsonaro quer general como no 2 da Saúde para montar equipe provisória. Portal Folha, 2020. Disponível em: https://www1.folha. uol.com.br/cotidiano/2020/04/bolsonaro-quer-general-como-no-2-da-saude-para-montarequipe-provisoria.shtml. Acesso em: 24 maio 2020.

CARVALHO, I. Com 20 militares, Ministério da Saúde pode mudar narrativa da pandemia. Portal Brasil de Fato, 2020. Disponível em: https://www.brasildefato.com.br/2020/05/25/com20-militares-ministerio-da-saude-pode-mudar-narrativa-da-pandemia . Acesso em: 18 set. 2020. DOMENICI, T. Caminho de Bolsonaro ao poder seguiu "lógica da guerra”, diz antropólogo que estuda militares. Portal PUBLICA, 2019. Disponível em: https://apublica.org/2019/04/ caminho-de-bolsonaro-ao-poder-seguiu-logica-da-guerra-diz-antropologo-que-estudamilitares/. Acesso em: 24 maio 2020.

ESTADÃO. Militares ganham funções estratégicas no Ministério da Saúde. Portal Estado de Minas, 2020. Disponível em: https://www.em.com.br/app/noticia/politica/2020/05/07/ interna_politica,1145232/militares-ganham-funcoes-estrategicas-no-ministerio-da-saude. shtml . Acesso em: 24 maio 2020.

FREIRE, S. Governo Bolsonaro é aprovado por 49\% e desaprovado por 44\%. Portal poder 360. Disponível em: https://www.poder360.com.br/poderdata/governo-bolsonaro-e-aprovado-por49-e-desaprovado-por-44/. Acesso em: 18 set. 2020.

GAGLIONI, C. Teich caiu: o ministro da Saúde que durou menos de um mês. Portal NEXO, 2020. Disponível em: https://www.nexojornal.com.br/expresso/2020/05/15/Teich-caiu-oministro-da-Sa\%C3\%BAde-que-durou-menos-de-um-m\%C3\%AAs . Acesso em: 24 maio 2020. 
GULLINO, D. 'Vai botar mais militares, sim, com civis não deu certo', diz Bolsonaro sobre Ministério da Saúde. Portal O Globo, 2020. Disponível em: https://oglobo.globo.com/sociedade/ vai-botar-mais-militares-sim-com-civis-nao-deu-certo-diz-bolsonaro-sobre-ministerio-dasaude-24442108. Acesso em: 24 maio 2020.

JUCÁ, B. Mandetta diz não ter aceitado a demissão de Wanderson e que equipe trabalhará junta até sua saída. Portal El País, 2020. Disponível em: https://elpais.com/Comentario/1586981022d6b1d31a0fa2198c913a0c62934b8b90?gla=pt-br . Acesso em: 24 maio 2020.

KISS, C.; GONÇALVES, L. A. P. Labirinto da saúde no Brasil: a pandemia e o minotauro. Physis, Rio de Janeiro, v. 30, n. 3, p. e300305, 2020. Disponível em: <http://www.scielo.br/ scielo.php?script=sci_arttext $\&$ pid $=S 0103-73312020000300304 \& \operatorname{lng}=e n \& \mathrm{nrm}=\mathrm{iso}>$. Acesso em: 18 set. 2020. https://doi.org/10.1590/s0103-73312020300305.

MOURÃO, A. H. M. Limites e responsabilidades. Portal Estadão, 2020. Disponível em: https:// opiniao.estadao.com.br/noticias/espaco-aberto,limites-e-responsabilidades, 70003302275. Acessado em: 24 maio 2020.

NEVES, J.; MACHADO, K. Atenção primária à saúde terá novo modelo de financiamento. Portal EPSJV/Fiocruz, 2019. Disponível em: http://www.epsjv.fiocruz.br/noticias/reportagem/ atencao-primaria-a-saude-tera-novo-modelo-de-financiamento . Acesso em: 24 maio 2020.

PAIM, J. S. A reforma sanitária brasileira e o Sistema Único de Saúde: dialogando com hipóteses concorrentes. Physis, Rio de Janeiro, v. 18, n. 4, p. 625-644, 2008. Disponível em: <http://www. scielo.br/scielo.php?script=sci_arttext $\&$ pid $=$ S0103-73312008000400003\&lng=en \& $\mathrm{nrm}=$ iso $>$. Acesso em: 18 set. 2020. https://doi.org/10.1590/S0103-73312008000400003.

ROMAN, A. O viés de seleção dos entrevistados pode impactar os resultados das recentes pesquisas de opinião? Portal El País, 2020. Disponível em: https://brasil.elpais.com/ opiniao/2020-05-13/o-vies-de-selecao-dos-entrevistados-pode-impactar-os-resultados-dasrecentes-pesquisas-de-opiniao.html. Acesso em: 24 maio 2020.

SAÚDE POPULAR. Rede de médicos populares denuncia as contradiçóes do programa federal. Portal BRASIL DE FATO, 2019. Disponível em: https://www.brasildefato.com.br/2019/08/05/ rede-de-medicos-populares-denuncia-as-contradicoes-do-programa-federal . Acesso em: 24 maio 2020.

SILVA, R. D. F .C.; GONÇALVES, L. A. P. As pílulas do Messias: salvação, negação e política de morte em tempos de pandemia. Portal do Instituto de Medicina Social, 2020. Disponível em: https://www.ims.uerj.br/wp-content/uploads/2020/04/physis30_2_a08.pdf . Acesso em: 25 maio 2020.

SHALDERS, A. Governo Bolsonaro: quem é Luiz Henrique Mandetta, que será ministro da Saúde. Portal BBC, 2018. Disponível em: https://www.bbc.com/portuguese/brasil-46282841 . Acesso em: 24 maio 2020. 